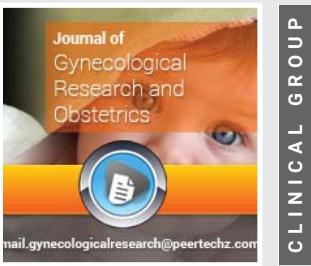

\title{
Sonographic Criteria for Earlier Detection of Molar Pregnancies
}

\author{
Gupta N*, Botros S, Demetrios M and Blankstein J \\ Department of Obstetrics and Gynecology, Mount Sinai Hospital, Chicago, IL, 60608, USA
}

Check for updates

Received: 17 February, 2020

Accepted: 25 April, 2020

Published: 27 April, 2020

*Corresponding author: Natasha Gupta, Department of Obstetrics and Gynecology, Mount Sinai Hospital, Chicago, IL, 60608, USA, E-mail: docnatasha3@gmail.com

Keywords: Gestational trophoblastic disease; Ultrasound; Diagnostic criteria; snowstorm

https://www.peertechz.com

\begin{abstract}
Objective: To establish the sensitivity of ultrasonography as a diagnostic tool in the early identification of molar pregnancies and to develop a sonographic diagnostic criterion in earlier detection of molar pregnancies.

Methods: A case series study was implemented for 69 patients who were found to have a diagnosis of molar pregnancy, confirmed histologically by the pathology department. This retrospective study investigated these patients at Mount Sinai Hospital between 2014-2016. Study groups were defined and compared by sonographic findings based on the presence of a gestational sac, yolk sac, fetal pole and appearance of the uterine cavity. Additionally, the presence of theca- luteal cysts, size of the ovaries, uterine size, and endometrial thickness were examined as well.

Results: of the 69 patients diagnosed pathologically with molar pregnancies, 48 had received ultrasounds for initial evaluation upon presentation. 27 of these patients showed sonographic features suggestive of molar pregnancies; 24 displayed the multi-cystic mass change, with an incidence of $89 \%$. The incidence of visualization of the additional findings in these 27 cases were: a gestational sac (GS) (74\%), a fetal pole (41\%), uterine enlargement (33\%) and the snowstorm appearance (19\%). The 21 cases that did not show any sonographic evidence of molar pregnancies were diagnosed as: 10 missed abortions ( $21 \%), 4$ early pregnancies ( $8 \%), 4$ blighted ovums ( $8 \%)$, 1 ectopic pregnancy ( $2 \%), 1$ early congenital anomaly ( $2 \%)$ and 1 inevitable abortion ( $2 \%)$. The imaging findings were compared in all patients with the histological material from endometrial curettage and /or hysterectomy.
\end{abstract}

Conclusion: The presence of cystic changes of the endometrium and increased placental heterogeneity allows us to successfully diagnose and treat molar pregnancies during the first trimester. This method allows for earlier diagnosis than the "gold standard" snowstorm appearance; which is best visualized during the second or third trimester.

\section{Introduction}

For years, it has been the accepted standard for hydatiform molar pregnancies to be recognized by ultrasound examination during the second trimester [1]. Medical literature depicts, in late pregnancy, these moles as a uterine cavity filled with heterogenous mass as well as anechoic spaces of varying size and shape, no fetal development and large ovarian cysts [2-4].

Such advancement in disease detection has made the once hallmarked "typical mixed echogenic pattern" no longer seen [5]. This pattern replaces the placenta. It is produced by the villi and intrauterine blood clots. Since most cases of molar pregnancies are evacuated in the first trimester, these typical sonographic presentations are now rarely encountered $[2,6]$. For reasons unknown, the incidence of moles varies by race and age. Hydatiform mole occurs at present in approximately
1 in 2000 pregnancies in Europe and the United States, but the rate approaches 1 in 500 in Japan, Singapore and Malaysia. A significant increase in the incidence of moles has been observed in women after age 40 and in women 20 years and younger.

Gestational Trophoblastic Disease (GTD) is a spectrum of interrelated disease processes that originate from the placenta. Hydatiform mole and invasive moles are 2 subgroups comprising GTD. Invasive moles can be further broken down into: choricarcinoma and the rare Placental Site Trophoblastic Tumor (PSTT).

The hydatiform mole is represented by villi, composed of trophoblastic tissue, that become edematous and proliferate. When a hydatiform mole locally invades the myometrium, it is called chorioadenoma destruens. This is one of the invasive groups of moles. Choriocarcinoma, the other type of invasive 
mole, is noted for its widely metastatic invasion [7,8]. These are composed of malignant trophoblastic cells but lack hydropic villi. The malignant tumors develop following formation of a hydatiform mole. Placental Site trophoblastic tumors are rare and consist of intermediate trophoblastic cells that persist after a term pregnancy. These tumors may invade adjacent tissues or even metastasize [8].

$95 \%$ of hydatiform moles are complete moles, which result from the fertilization of an empty ovum by a normal sperm. Patients deficient in carotene or animal fat in the diet, increased maternal age, history of spontaneous abortions, infertility and previous molar pregnancies are particularly susceptible to these moles. Molar pregnancies typically present with painless vaginal bleeding in the fourth- fifth month of pregnancy. The uterine size typically surpasses the correlating gestational age and ovarian enlargement may be observed as well [9]. Excessive vomiting more exaggerated than hyperemesis gravidarum may be noted in these patients. The clinical diagnosis is based on assessing beta- hcg levels that may reach measurements greater than 100,000 mIU/ ml. Clinical features consist of excessive vomiting, transient hyperthyroidism, palpitations and elevated BPs. However, USG and histopathological examinations are used for the definitive diagnosis [9].

\section{Methods}

We performed a retrospective analysis of 69 cases. These cases consisted of patients that were histologically diagnosed with GTD between the years of 2014-2016 in Mount Sinai Hospital, Chicago, IL. In reviewing these 69 cases, it was found that only 48 of the cases had an ultrasound performed. The 48 sonographic findings were studied and compared with the histological material from endometrial curettage and/ or hysterectomy. Results preceding ultrasound examination were documented and a review of USG findings and final histological diagnosis was carried out. All 69 cases were pathologically verified to be molar pregnancies.

Of the 69 consecutive cases that were examined, the average maternal age was 28 years. The average gestational age was 9 weeks and, if present, the typical presenting complaints were painless vaginal bleeding. Of the ultrasonographic findings that were compared in all patients with histological material from endometrial curettage and or hysterectomy, the findings seen included, but not limited to: miscarriages, complete moles, and partial moles.

\section{Results}

Of the 69 pregnant patients that were pathologically confirmed to have had molar pregnancies, 48 cases were found to have had an ultrasound performed. Of the 48 sonographic cases:

$$
27 \text { confirmed GTD (56\%) }
$$

10 confirmed missed abortion (21\%)

4 confirmed early pregnancy $(8 \%)$

\section{4 confirmed blighted ovum (8\%)}

1 confirmed an ectopic pregnancy ( $2 \%)$

1 confirmed an early congenital anomaly ( $2 \%)$

1 confirmed an inevitable abortion ( $2 \%)$

Of the 48 ultrasounds, the 27 confirmed molar pregnancies showed specific ultrasonographic characteristics associated with GTD. Of these 27 confirmed molar pregnancies, 24 of those ultrasounds showed an intrauterine multi-cystic mass. This finding was the most consistent among the various ultrasounds, as the incidence of this finding was significant $(89 \%)$. The gestational sac was visualized in $74 \%$ of these cases as well, making this an important identifying marker in suspected cases of molar pregnancy. Fetal poles were noted on ultrasound in $41 \%$ cases, and uterine enlargement was seen in $33 \%$ cases. As seen in these results, the characteristic: snowstorm" appearance is represented the smallest percentage $(19 \%)$ cases.

Of the 69 cases, 21 were directly sent to the operating room, with no ultrasounds performed, for an immediate dilatation and curettage. This data helps to identify specific diagnostic criteria that can be used in the future to determine molar pregnancies earlier than the current methods allow.
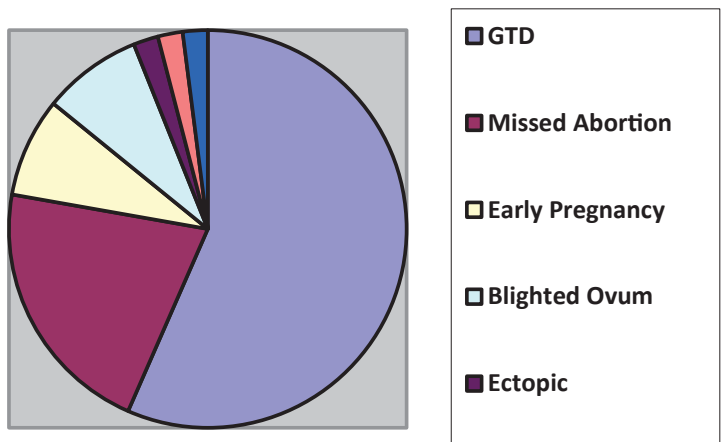

Pie graph demonstrating definitive diagnosis based on ultrasound, in suspected molar pregnancies.

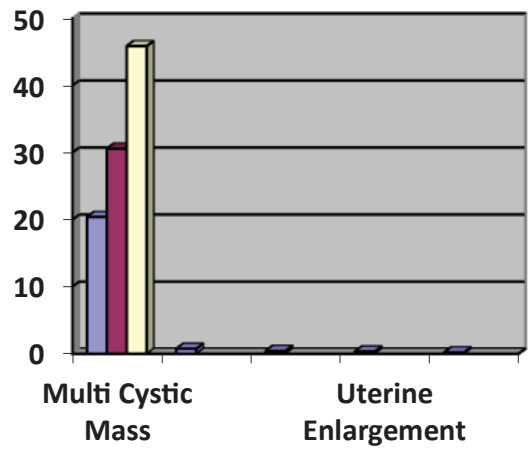

$\square 89 \%$

0

Graphic representation of ultrasound findings for the 27 molar pregnancies where ultrasound was utilized.

Citation: Gupta N, Botros S, Demetrios M, Blankstein J (2020) Sonographic Criteria for Earlier Detection of Molar Pregnancies. J Gynecol Res Obstet 6(1): 004-007. DOI: https://dx.doi.org/10.17352/jgro.000076 


\section{Discussion}

With the advent of early molar pregnancy detection, the purpose of our study was to demonstrate the existence of unique highly sensitive sonographic criteria for the diagnosis of these molar pregnancies in the first and early second trimester. This retrospective case study was carried out to identify patients with the primary diagnosis of possible molar pregnancies, that presented to Mount Sinai Hospital in Chicago, Chicago, IL from 2014-2016. Ultrasonography was performed on 48 of the 69 patients suspected of having molar pregnancies. The results reported included: presence of GS, YS, fetal pole, fetus and various descriptions of the appearance of the uterine cavity. This appearance includes the presence of the infamous snowstorm pattern, multicystic presentation, otherwise termed swisscheese pattern. Other findings that were reported included the presence of theca-luteal cysts, the size of the right and left ovaries, the uterine size and endometrial thickness.

The patients were treated with an endometrial curettage and / or hysterectomy. Histological specimen was collected during the surgical procedures. These specimens were reviewed by an expert pathologist and subsequently compared with the sonographic findings obtained earlier. The comparison of these sonograms with the specimen allowed for definitive diagnosis of molar pregnancies in these cases. Of the 69 cases, the 21 that did not get ultrasound were directly sent to the operating room for an immediate dilatation and curettage.

Several studies have now reported the use of ultrasound for the detection of hydatiform moles in early pregnancy. Fine et al, in their sonographic study of hydatiform molar pregnancies, reported finding cystic changes and increased placental echogenicity [10]. Concurrently, Jauniaux et al reported that 10 of 11 pregnancies with sonographic features suggestive of hydatiform moles, at 10-14 weeks of gestation, were proven pathologically post evacuation [11]. During the first trimester of molar pregnancies, the expected hydatiform ultrasound characteristics are less readily apparent. Subsequently, two larger, more recent studies have reported that correct preevacuation identification of molar pregnancies by USG is achieved in 40-60\% cases in the first and early second trimester. In these, more recent studies, the main sonographic findings in early molar pregnancy appeared to be cystic changes of the endometrium, increased placental heterogeneity and hyperechogenic masses filling the uterine cavity $[4,12]$.

Based on the evidence identified by previous research, our study sought to exhibit the sensitivity of ultrasound and the most sensitive sonographic criteria for the diagnosis of molar pregnancies in the first and early trimester. Our study reporting $56 \%$ sensitivity, is consistent with recent studies that reported $40-60 \%$ sensitivity of ultrasound in diagnosing first trimester molar pregnancies with new sonographic criteria. Our results confirmed that cystic changes of the endometrium and increased placental heterogeneity, seen on ultrasound are the key diagnostic features in evaluating molar pregnancies in the first trimester.
Due to the progression of medical advancement, ultrasound has replaced all other means for early screening and has helped in establishing the differential diagnosis of molar pregnancies in-utero. Traditionally, the sonographic finding of the "snowstorm" appearance has been the hallmark of diagnosis. Our study shows this hallmark is apparent in only $19 \%$ of molar pregnancies. Thus, this feature should not be relied on as diagnostic when evaluating molar pregnancies in first trimester pregnancies. However, thanks to the advancement of medicine, this late pathognomonic finding is becoming obsolete based upon our evolving ability to diagnose GTD early on during the first trimester of pregnancy rather than the second trimester.

\section{Conclusion}

Our study evaluated the sonographic features of molar pregnancy in early pregnancy among patients that presented between 2014 to 2016. This time period was chosen as the sonographic findings were reliably available for this duration. The typical second trimester sonographic features of molar pregnancies cannot be used for diagnosis of this condition in first trimester, instead cystic changes in endometrium and increased placental heterogeneity should be more commonly utilized.

\section{References}

1. Jain KA (2005) Gestational trophoblastic disease: pictorial review. Ultrasound Q 21: 245-253. Link: https://bit.ly/3eRDrZW

2. Benson CB, Genest DR, Bernstein MR, Soto-Wright V, Goldstein DP, et al (2000) Sonographic appearance of first trimester complete hydatidiform moles. Ultrasound Obstet Gynecol 16: 188-191. Link: https://bit.ly/2ylj0yd

3. Desai RK, Desberg AL (1991) Diagnosis of gestational trophoblastic disease: value of endovaginal color flow Doppler sonography. AJR Am J Roentgenol 157: 787-788. Link: https://bit.ly/3bHpn3i

4. Kirk E, Papageorghiou AT, Condous G, Bottomley C, Bourne T (2007) The accuracy of first trimester ultrasound in the diagnosis of hydatidiform mole. Ultrasound Obstet Gynecol 29: 70-75. Link: https://bit.ly/2y0p9pf

5. Woo JS, Hsu C, Fung LL, Ma HK (1983) Partial hydatidiform mole: ultrasonographic features. Aust N Z J Obstet Gynaecol 23: 103-107. Link: https://bit.ly/2KzxQcQ

6. Johns J, Greenwold N, Buckley S, Jauniaux E (2005) A prospective study of ultrasound screening for molar pregnancies in missed miscarriages. Ultrasound Obstet Gynecol 25: 493-497. Link: https://bit.ly/2KzTdec

7. Green CL, Angtuaco TL, Shah HR, Parmley TH (1996) Gestational trophoblastic disease: a spectrum of radiologic diagnosis. Radiographics 16: 1371-1384 Link: https://bit.ly/2Kvjb2o

8. Jauniaux E (1998) Ultrasound diagnosis and follow-up of gestational trophoblastic disease. Ultrasound Obstet Gynecol 11: 367-377. Link: https://bit.ly/3azNFuz

9. Sebire NJ, Rees H, Paradinas F, Seckl M, Newlands E (2001) The diagnostic implications of routine ultrasound examination in histologically confirmed early molar pregnancies. Ultrasound Obstet Gynecol 18: 662-665. Link: https://bit.ly/3aAOzJi

10. Fine C, Bundy AL, Berkowitz RS, Boswell SB, Berezin AF, et al. (1989) Sonographic Diagnosis of Partial Hydatiform Mole. Obstet Gynecol 73: 414 418. Link: https://bit.ly/2VzTIv5

Citation: Gupta N, Botros S, Demetrios M, Blankstein J (2020) Sonographic Criteria for Earlier Detection of Molar Pregnancies. J Gynecol Res Obstet 6(1): 004-007. 
11. Jauniaux E, Nicolaides KH (1997) Early ultrasound diagnosis and followup of molar pregnancies. Ultrasound Obstet Gynecol 9: 17-21. Link: https://bit.ly/3axsoBL
12. Fowler DJ, Lindsay I, Seckl MJ, Sebire NJ (2006) Routine pre-evacuation ultrasound diagnosis of hydatidiform mole: experience of more than 1000 cases from a regional referral center. Ultrasound Obstet Gynecol 27: 56-60. Link: https://bit.ly/3ePC030
Discover a bigger Impact and Visibility of your article publication with

Peertechz Publications

\section{Highlights}

* Signatory publisher of ORCID

* Signatory Publisher of DORA (San Francisco Declaration on Research Assessment)

* Articles archived in worlds' renowned service providers such as Portico, CNKI, AGRIS, TDNet, Base (Bielefeld University Library), CrossRef, Scilit, J-Gate etc.

* Journals indexed in ICMJE, SHERPA/ROMEO, Google Scholar etc.

* OAI-PMH (Open Archives Initiative Protocol for Metadata Harvesting)

* Dedicated Editorial Board for every journa

* Accurate and rapid peer-review process

* Increased citations of published articles through promotions

* Reduced timeline for article publication

Submit your articles and experience a new surge in publication services (https://www.peertechz.com/submission).

Peertechz journals wishes everlasting success in your every endeavours.

Copyright: @ 2020 Gupta N, et al. This is an open-access article distributed under the terms of the Creative Commons Attribution License, which permits unrestricted use, distribution, and reproduction in any medium, provided the original author and source are credited.

Citation: Gupta N, Botros S, Demetrios M, Blankstein J (2020) Sonographic Criteria for Earlier Detection of Molar Pregnancies. J Gynecol Res Obstet 6(1): 004-007. DOI: https://dx.doi.org/10.17352/jgro.000076 